\title{
What the World Needs Now is Love, Sweet Love (Punks)
}

DEBRA MYERS
CREATIVE PRODUCER, YIJALA YALA PROJECT
AND
DAVE PALMER
MURDOCH UNIVERSITY

In a small, remote town in Western Australia, arts and social change organisation Big hART developed a way of working with young people disengaged from education. A process of engagement through popular entertainment modes such as comics and computer games introduced young people to the concept of conserving and transmitting their culture. Funding support from a resource company and building relationships with several local cultural organisations allowed for this project to grow over time and be shaped by the challenges and strengths of the community as well as the ambitions, gifts and personalities of the individuals involved. 
Situated fifteen hundred kilometres north of state capital Perth, Roebourne (Ieramugadu) is one of the oldest towns in the harsh but beautiful West Pilbara region of Western Australia. From the late nineteenth century to the 1960s, Roebourne was the largest settlement between Darwin and Perth and supported extended periods of mining for precious resources such as gold, copper and tin. In the 1960s-with the exponential growth in iron ore mining-Roebourne boomed suddenly and then almost overnight saw the removal of infrastructure, jobs and a future, as larger modern company towns were created to support the resources boom. As a result, Roebourne lost the majority of its non-Aboriginal population, while maintaining itself as home to families with Ngarluma, Yindjibarndi, Kuruma, Marthudunera, Yaburrara and Banyjima heritage. Currently, the relatively young population stands at 950 and is growing. Many Roebourne families have a tough history. Until the 1960s there were strict controls and curfews placed on people's movement to and within the town. Indeed, most of the senior people grew up confined to a reserve on the other side of the Ngurin (Harding) River, before being moved into government-built houses in the town during the 1970s. Today many complex and multi-layered challenges face these same extended families. One of the most crucial is that many of the young people growing up in Roebourne are missing out on education as they don't often attend school and there are no learning alternatives on offer.

One of the layers of complexity in Roebourne is the obligation of resource companies that enter into land use agreements with traditional owner groups to deliver projects that have social or cultural benefits for the community.

Woodside Energy (Australia's largest independent oil and gas company, which operates two gas plants in the region) is one of these companies. In 2007, Woodside Energy entered into an agreement with the Commonwealth Government to support projects that work to protect, identify, manage and transmit knowledge regarding the heritage of the Dampier Archipelago. This area includes Murujuga (also known as the Burrup Peninsula) a UNESCO-listed heritage site that is home to over one million petroglyphs (etched rock art), some of which date back thirty thousand years. It is locally and internationally recognised as a site of great cultural significance, but is not widely appreciated in Australia in comparison to other places of cultural importance such as Kakadu or Uluru. 
It was within this context that Big hART, a not-for-profit, arts and social change organisation with a strong track record of running successful, long-term community cultural development projects, was invited by Woodside Energy to meet with community leaders and propose an inter-generational project that would create artworks related to the cultural heritage of Murujuga, while building digital, literacy and life skills of young people not attending school and adults in prison. The community members consulted were impressed with Big hART's previous work in Aboriginal communities through the Ngapartji Ngapartji ${ }^{1}$ and Namatjira ${ }^{2}$ projects, and they gave Woodside Energy permission to fund the project.

Since 1992 Big hART has been working in marginalised and disadvantaged communities across Australia. The company, established by playwright and director Scott Rankin, is made up of artists, community workers, researchers, film-makers, designers and producers who combine experience, experimentation, innovation and art-based project work with building the skills, interests and relationships of members of the community. New skills and capacity are brought to a community by outsiders, who come to live, listen and learn. Together they build relationships, hear old stories, create new ones, and find ways to symbolically and literally create new cultural opportunities to share the gifts and potential of a community with the world, in such a way that new local opportunities are also created. Previous projects with high profile art outcomes include Knot @ Home, Northcott Narratives, Drive, Ngapartji Ngapartji and Namatjira.

The Yijala Yala Project was created in the Pilbara region as a long-term, intergenerational, multi-platform arts project that set out to highlight cultural heritage as living, continually evolving and in the 'here and now' rather than something static. ${ }^{3}$ The project name Yijala Yala means 'now' in the two main regional languages of Yindjibarndi and Ngarluma. Yijala Yala works with members of the local Aboriginal community to create content that reflects cultural heritage in new ways, and is also created using new methods of teaching and skill-building. In other words, it approaches the idea of heritage work holistically, taking into account the shifts that will need to take place within individuals and the community to ensure that the skills, experience and desire required to carry out vital cultural heritage conservation work in the future are built. Along with meeting the Woodside/Australian Government Conservation Agreement objectives, the project 
design was based on feedback and requests from the community about what they deemed were priorities, such as working with the kids who don't attend school and prisoners and getting kids to engage more with traditional culture rather than playing computer games and watching films.

Big hART learned of the young people's interest in film and computer games, and recognised that in Roebourne, as in many communities, there are many skills, gifts and great cultural depth, already present, but hidden, as well as the chaos and everyday survival issues that disrupt traditional rigid educational approaches. In response, they wanted to trial a skill-building process that removed obstacles to education and built on the interests of young people, with cultural leadership provided by parents and grandparents.

In the early stages of the Yijala Yala project, Big hART set out to begin building digital media skills, creating content and passing on stories through everyday technologies such as mobile phones, computers, television and radio. A group of fifteen boys, a worker from a resource company and two young mothers came together under the mentorship of a professional filmmaker, choreographer and actor to make a short film exploring the energy of young people and how that can generate fresh ideas and change. The result was a comic film called Love Sweet Love Punks that explored how the high-energy of young people could wake-up adults stuck in their day-to-day existence, and utilised pop-culture themes such as zombies and post-apocalyptic punk juxtaposed against the simplistic sentimentality of the Burt Bacharach song 'What the World Needs Now (Is Love Sweet Love)'. The process included workshops in camera and sound set up, operation and technique; steady camera operation; sound composition; song writing; lighting; set design; choreography; costume design and makeup; acting; directing, photography; and behind the scenes documentary film-making. It provided young people with a chance to have fun, create contemporary stories, star in a short film and to become engaged in new forms of cultural activity.

Big hART workers saw how much young people loved working on this small project and how involved they became with technology such as phones, cameras, computers and iPads whenever they had the chance. During the third term of school, Big hART digital media artist and illustrator Stu Campbell teamed up with the IT and computing teacher at the local school. The school principal supported this working 


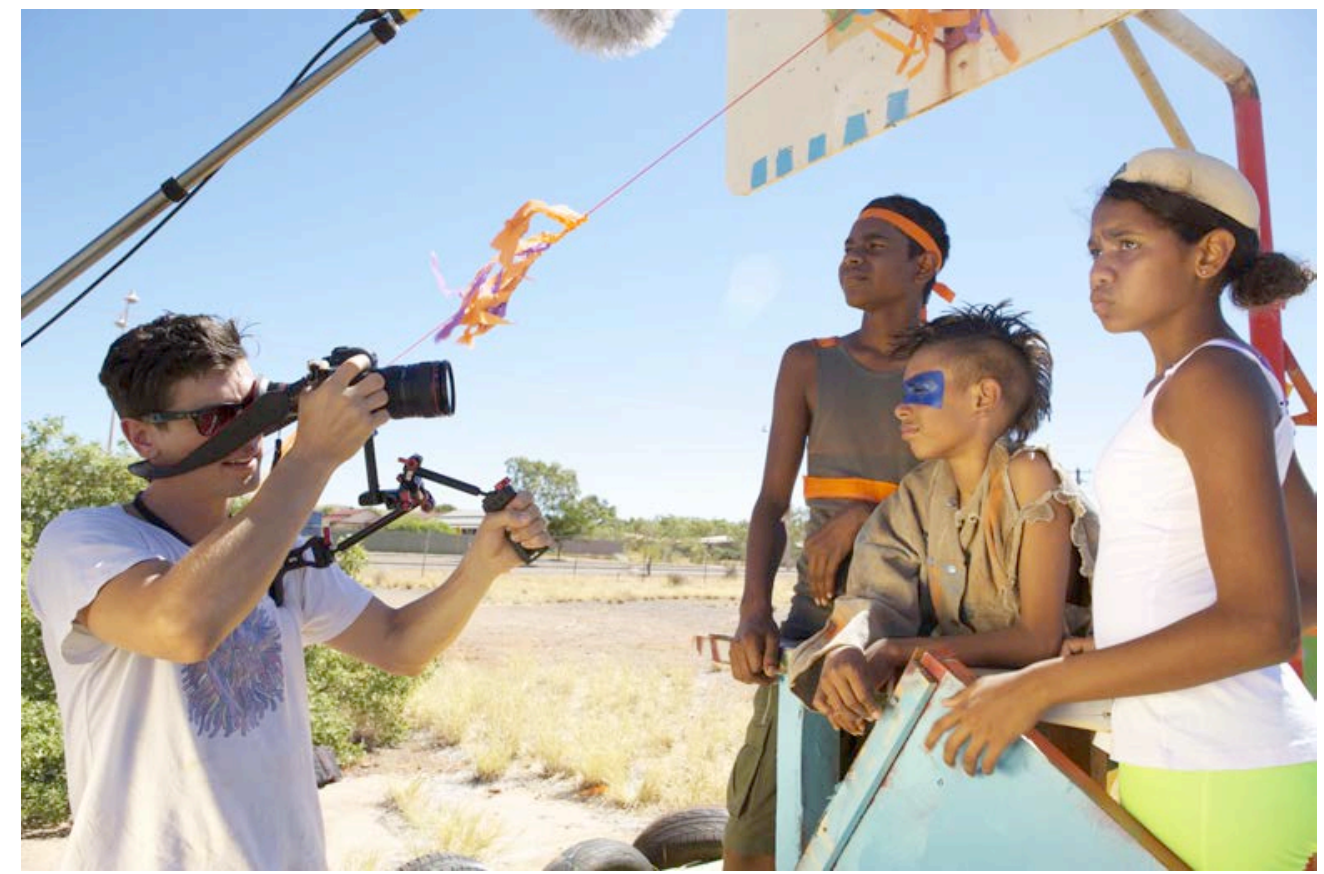

Image 1: Shooting film component of the comic, Benjamin Ducroz, Claude Eaton, Maverick Eaton and Alison Lockyer (photograph: C. Campbell: image @ Big hART)

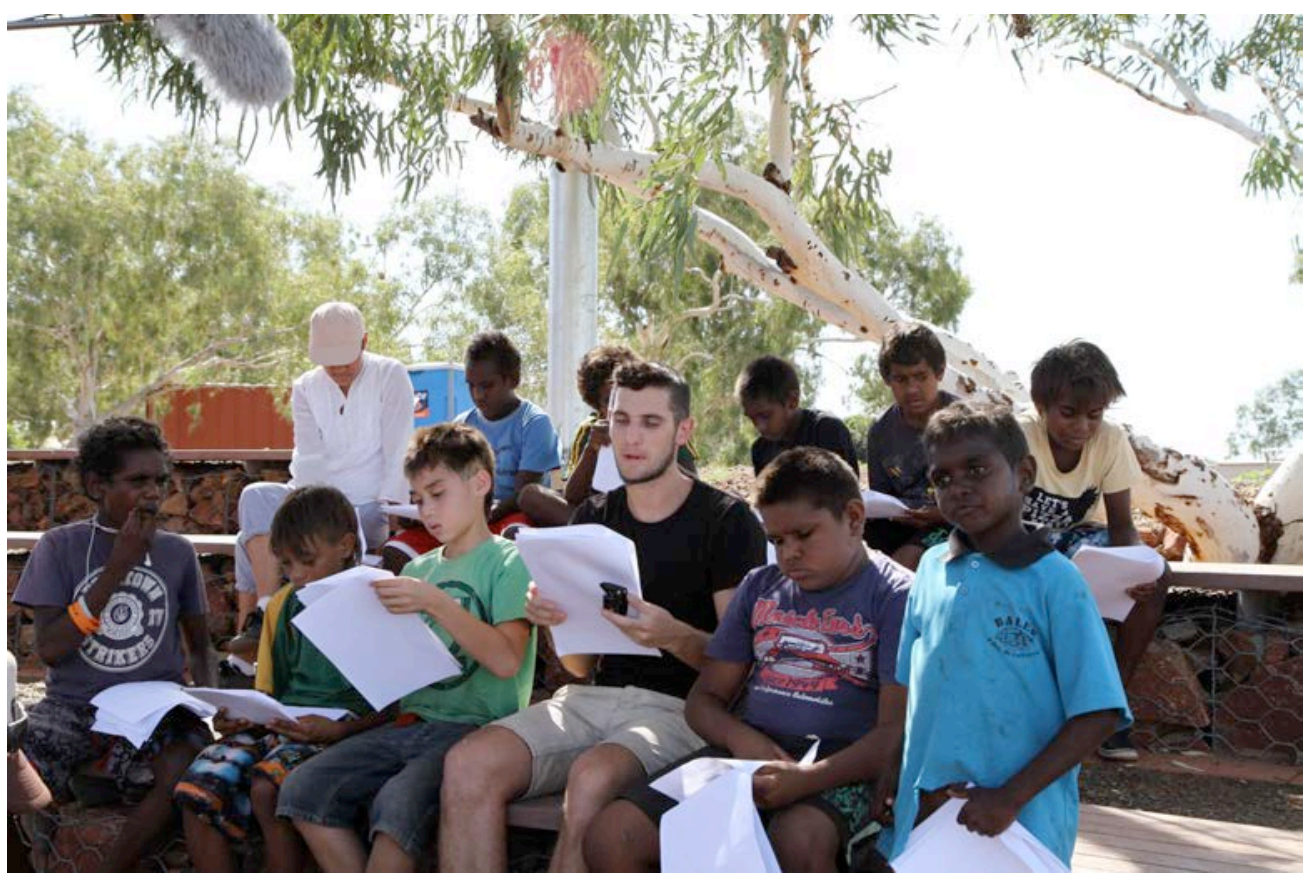

Image 2: First script reading for Love Punks digital comic, Back: Mariaa Randall, Max Coppin, Eric Wegde, Troydan Long and Nathaniel Edwins; Front: Corbyn Munda, Maverick Eaton, Brodie Tahi Tahi, Stu Campbell, Jordan Coppin and Jahmal Munda, February 2012 (photograph: C. Campbell; image @ Big hART) 
relationship by purchasing multiple Photoshop licences, and digital tablet producing company Wacom generously donated five electronic tablets to be used in the workshops. Together this partnership between school, community and the corporate sector provided a way of incorporating Stu Campbell's skills and ideas into the classroom curriculum using stop-motion animation. The strength of the idea was to combine training in stop-motion animation with class teaching, and at the same time provide workshops after school hosted by Big hART. To begin with, existing footage was used from earlier film-making workshops where the young people had featured as 'Love Punk' characters. The footage was broken down into frames and students were asked to remove their character images from the background. To do this, they learnt to create a file, import an image for stop-motion animation, make a mask and navigate through the animations once they were created.

As the Roebourne District High School, IT and computing teacher Mr Kane Guy explained:

The students then took turns working with Stu to cut themselves out of the backgrounds to be placed into the digital landscape that he had created. This was teaching them two different ways of achieving a very similar outcome and giving them experience with the tools needed to create stop motion animation and use Photoshop. This pathway was fantastic and made my lessons easier to plan and all the richer for demonstrating the positives of the collaboration.

These workshops ran four days a week at the school and soon became so popular that several students began working with Stu after school in the Big hART digital media room. Through these workshops, over two thousand frames of animation were created for an interactive online game, www.lovepunks.com, that animates community as a magical place and invites players to explore and see the town as kids do. One of the most important elements in this style of teaching was that the kids were able to see their work coming together to create something big. The pride they felt when the game was completed, online, and shared with the community was enormous. Further positive reinforcement came at an end of year school concert when Stu joined other teachers in awarding certificates to students who had excelled in the digital media classes. 


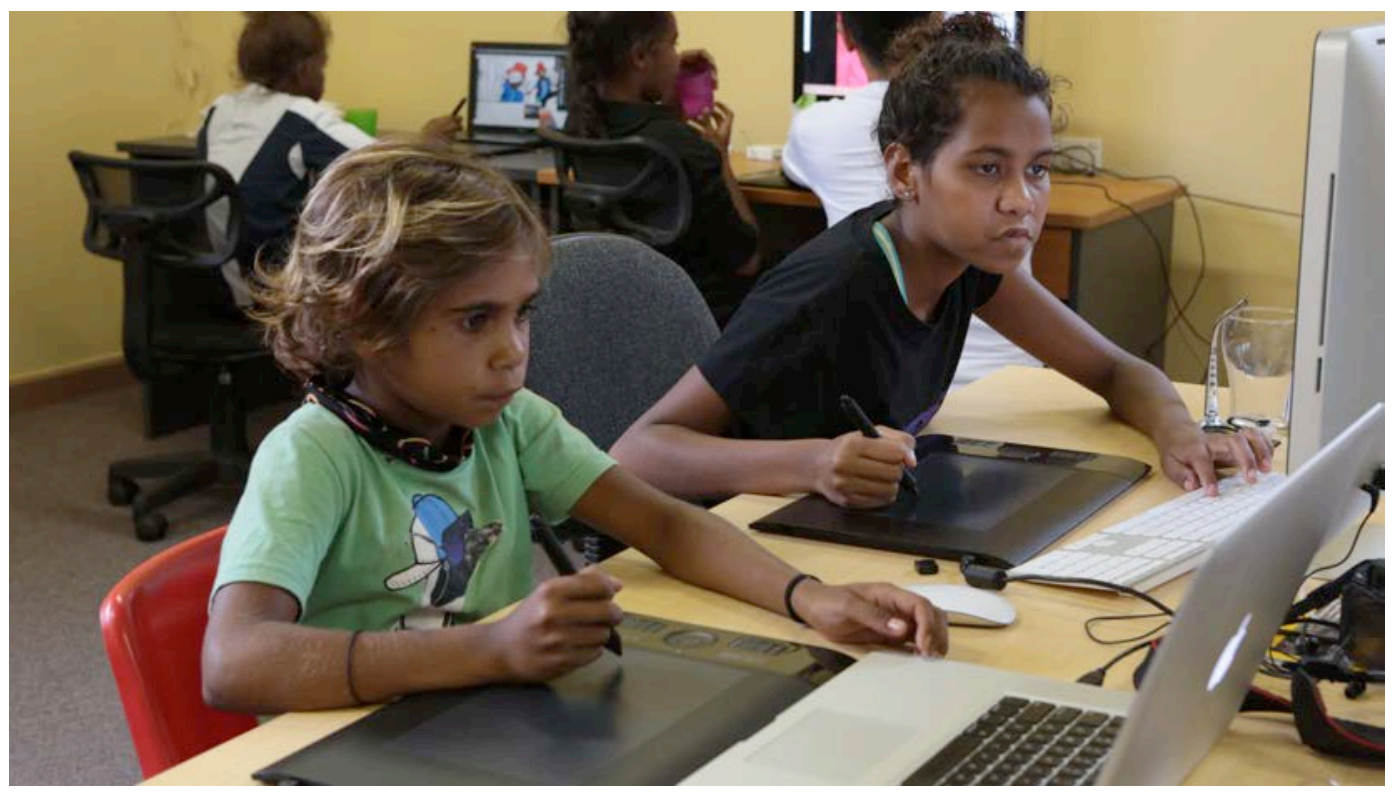

Image 3: Wally Snook and Alison Lockyer working on NEOMAD during after school workshops, February 2013 (photograph: C. Campbell; image @ Big hART)

One profound moment in the development of this work was during an early workshop in the Big hART office. Stu had been working with kids, sharing animation software with one particularly talented kid while the other two watched from behind. At one point the young man proceeded to demonstrate his prowess by wrestling the tablet and digital pen from Stu. Keen to further show his mastery, he asked Stu to give up sitting in the 'driver's seat' so he could teach the skill of animation to both his peers.

Love Punks momentum continued to grow. One day a new student came to the Big hART office, keen on becoming a Love Punk. One of the 'older' Love Punks offered to help him to create his look. He sketched his face paint design in Photoshop using a Wacom pen, then he showed him the colour palette and together they came up with a design. This was an exciting autonomous moment-not a planned part of the workshop-which the more experienced Love Punk initiated to exercise his skills. These were more advanced Photoshop skills than the kids had been learning and enabled Stu to move into the next phase of his teaching, which was for the kids to learn to colour their characters in the Neomad interactive comic.

Neomad continued the kids' skill development and engagement, but the story would feature Murujuga (the Burrup Peninsula), meeting one of the project 
objectives of working with funding sponsor Woodside to promote Murujuga as a significant cultural heritage site. Similarly to the game, Neomad was going to take several months of hard work, this time learning how to colour in black and white line drawings using the Wacom tablets and pens they had mastered while creating the game. This next phase of learning built on their prior knowledge and taught the students the following skills in Photoshop: selecting colour using the eyedropper tool; creating layers; breaking down the composition of a drawing, separating out elements in a picture and considering which layer comes first; depth perception; recognising and determining the light source in an image, and then rendering highlights and shadows.

Learning these new skills was made easier by the fact that again the young people were working towards a clear outcome-this time the launch of the comic on iTunes as a new micro-business for the community. 4 The Neomad process also created desire to be involved as young people were excited to link their fictional,screen-based selves with their real world lives and relationships. In Neomad their Love Punk characters became hyper-versions of themselves, living in the future of a world they knew well.

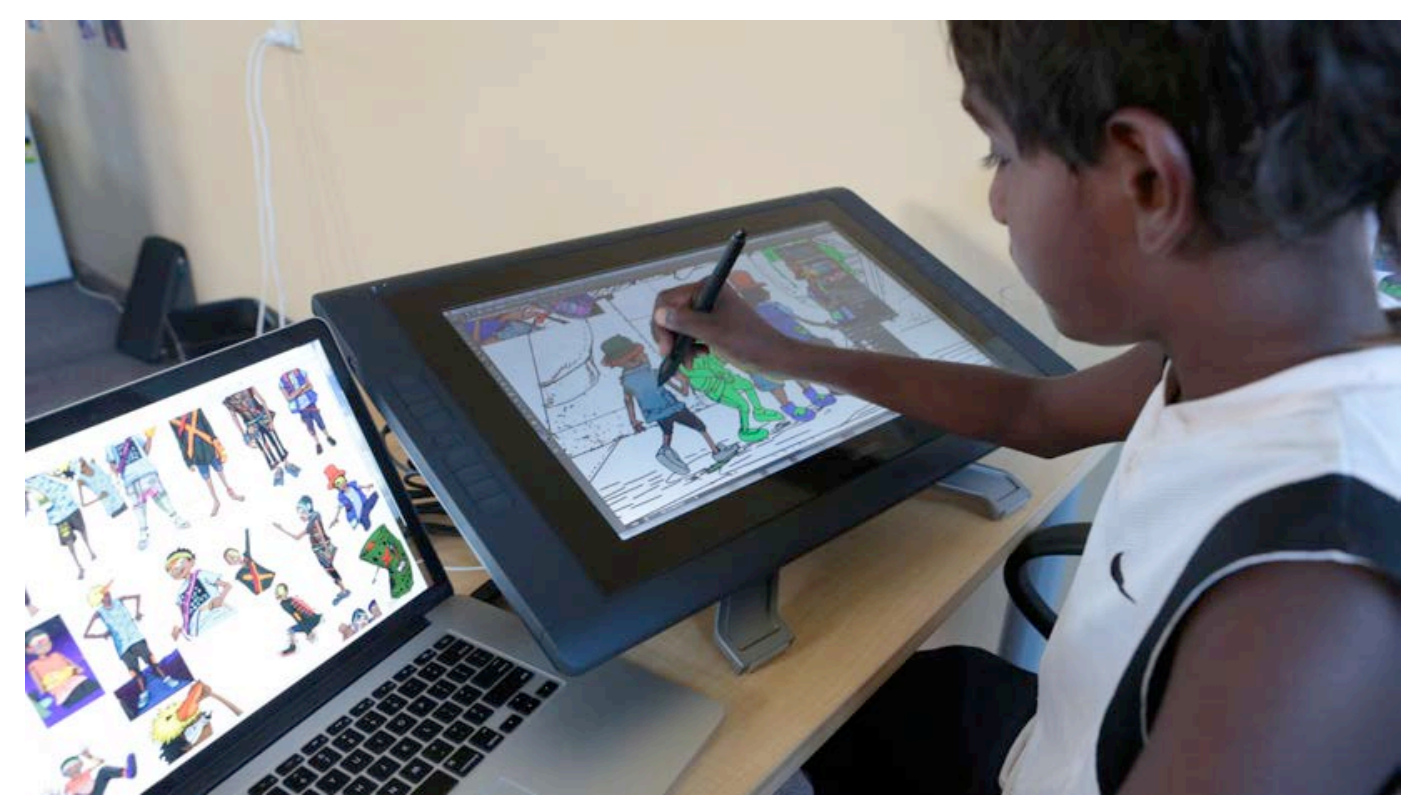

Image 4: Woedin Wilson working on NEOMAD, February 2013 (photograph: C. Campbell; image (C) Big hART) 
The comic involved more than two hundred scenes, with thirty young people, of whom fourteen are key characters, involved in seventy Photoshop workshops. They also recorded dialogue for their characters alongside senior community members who also had roles in the story, read scripts, and rehearsed and filmed five pages of complex dialogue for a live action film sequence that was incorporated into the start of the story. As Stu Campbell explains it:

The juxtaposition of live action with the comic helps to tell audiences that it is based on real people. It's really important that we continue to reinforce how the real world is constantly informing the fictional narrative. We've spent a long time with these kids to figure out ways that they can become genuine co-creators and authors of their own story. This comes through via the adoption of their vernacular and obviously their technical assistance.

There are also plans to have Neomad translated into the two local languages Ngarluma and Yindjibarndi to enable readers to toggle between and learn some of these languages. This has already been built in partially, and is hugely popular with the local community.

Neomad has already achieved much more than it was ever imagined it would. In June 2012, three Love Punks travelled away from home for the first time to preview Neomad at the Supanova Pop Culture Expo in Perth and experience the comic industry. The Bucheon International Comics Festival in South Korea then invited Stu, Nathaniel and Maverick to officially launch the comic and present its creative process at the festival. A high achievement for any artist, let alone an eleven-year-old artist from a remote Aboriginal community who only began learning the software nine months previously. They also ran a Photoshop and comic creation master class at ICCCF. Before leaving for South Korea, Maverick Eaton said 'I'm excited about teaching other people what we've done, so they can do it too.'

Following the Supanova and Bucheon experiences, several of the girls who have long been building their Photoshop skills to make the game and the first episode of Neomad, decided it was time their characters joined the story too. The Satellite Sisters were born and introduced in Neomad Episode 2. In March 2013, two of the Satellite Sisters travelled to Alice Springs for the Same but Different forum and showed their skills to forum delegates. In April 2013, Neomad was screened as part 


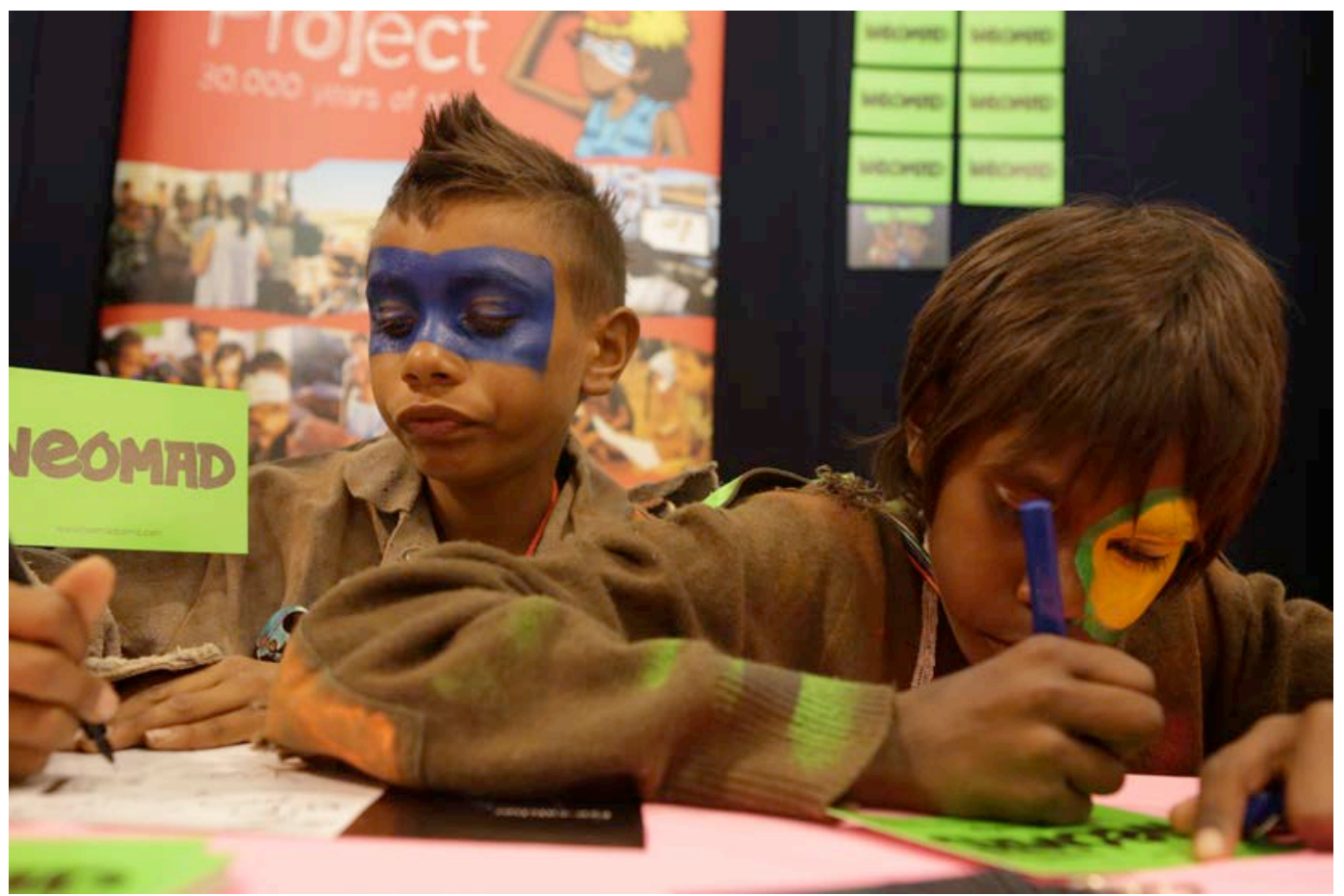

Image 5: Maverick Eaton, Eric Wedge, Supanova Pop Culture Expo, Perth, August June 2012 (photograph: C. Campbell; image @ Big hART)

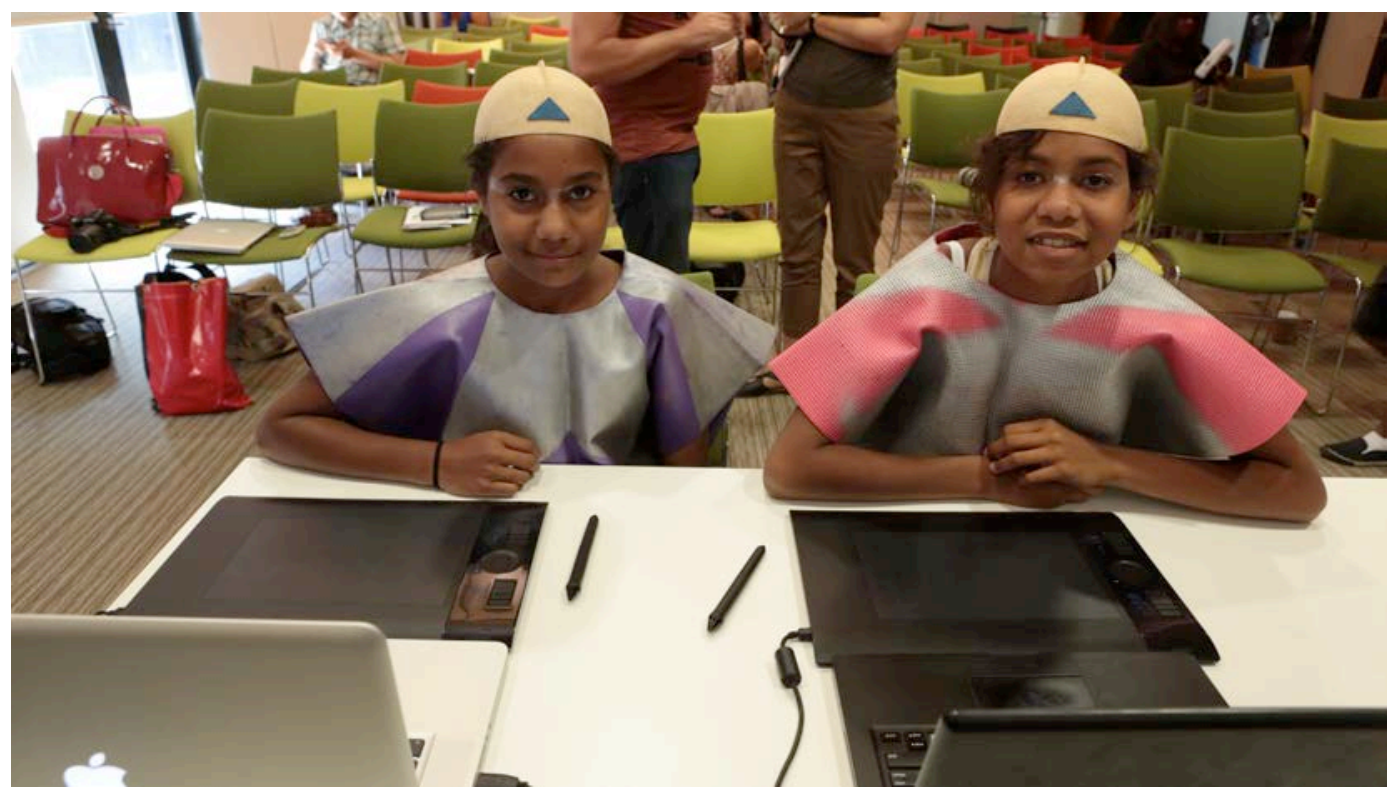

Image 6: Layla Walker and Alison Lockyer, Same but Different Forum, Alice Springs, March 2013 (photograph: C. Campbell; image @ Big hART and Same But Different) 
of a series of emergent desert animations at Same but Different Desert Animations in Sydney.

The success of the digital media program and the creation of Neomad is demonstrated by the continual uptake of participants. In Episode 1, there were nineteen young participants involved in production; by Episode 3 more than sixty young people were assisting with production (both during school workshops and after school hours). The core group of participants, who have been with the project since first making the game, have also been involved in the production of three digital storybooks-Warlu Song, ${ }^{5}$ Ngurrara $^{6}$ and Echidna and the Dress ${ }^{7}$-by senior men in the community, all now available for iPad from iTunes. The skills the young people learned continue to be of use, as shown by this email sent to the Big hART team recently by Alison Lockyer from her boarding school in Perth:

I forgot to tell you this last week when we were doing technology we did Photoshop. And it was so deadly all the memories started coming back to my head like how we went to Alice Springs and all that. Man I miss doingPhotoshop. And the teacher was like 'Have you done photoshop before?' Then I was like 'Yeah I did. I went to Alice Springs and showed them how Photoshop works.' And he was like 'Really?' and I was gonna say 'Yeah. what you haven't seen a blackfella do Photoshop before?' but I didn't. Man I miss you mob, I miss Photoshop, I miss filming and I miss acting.

Several of the young people are now in high school and a new group of younger kids became involved in more recent iterations of the process, which has involved the designing and colouring a Neomad road and community themed mural for the recreation precinct, with original Love Punks and Satellite Sisters joining in when they return to the community on school holidays. The Big hART team are now working on an education resource for primary school teachers to use Neomad in the classroom, and Scholastic have the books on their Book Club list, which means that the objective of creating interesting resources that convey the cultural significance of Murujgua as widely as possible is starting to be realised. 


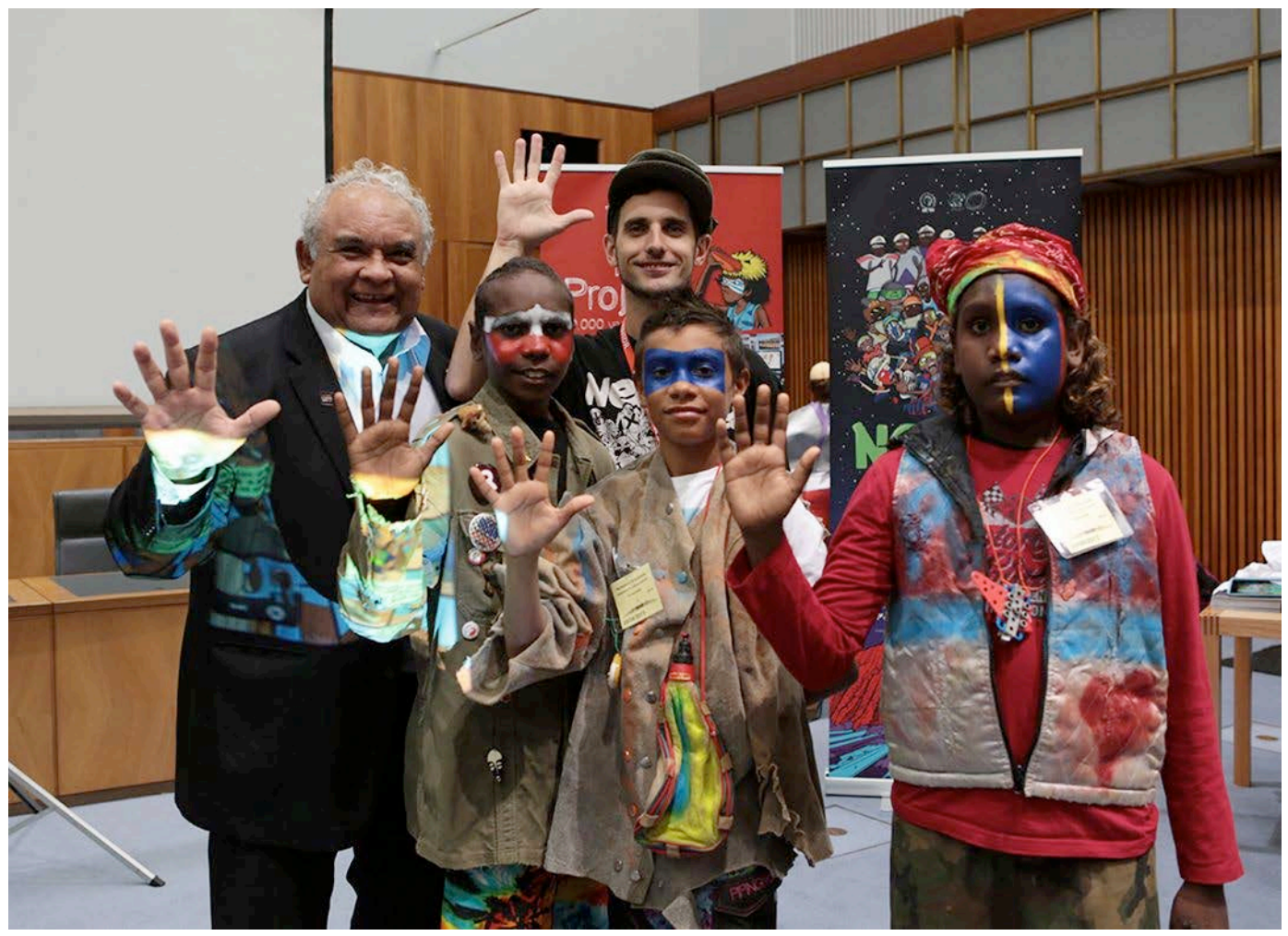

Image 7: Launching NEOMAD at Parliament House, Dr Tom Calma, Nelson Coppin, Stu Campbell, Maverick Eaton, Max Coppin, June 2013 (photograph: C. Campbell; image @ Big hART)

Debra Myers is an experienced arts manager, producer and community cultural development worker in the not for profit arts sector with organisations such as the Adelaide Festival, Ananguku Arts, Ernabella Arts and most recently with arts and social change organisation Big hART as the Creative Producer of the Yijala Yala Project from 2010 until early 2015. She is currently working with the Indigenous Affairs Group in the Department of Prime Minister and Cabinet.

Dave Palmer teaches in the Community Development Program at Murdoch University in Perth. He also spends a fair bit of time in remote Australia, looking for examples of projects having a positive impact on Indigenous young people's lives. He's come to the conclusion that in places like the southwest of WA, the Kimberley, the Pilbara, the Anangu Pitjantjatjara Yankunytjatjara (APY) Lands in Central 
Australia, Alice Springs town camps and the northwest of Tasmania, the use of culture, arts, performance, music, dance and film is often what makes a difference.

For more information: $<\underline{w w w . y i j a l a y a l a . b i g h a r t . o r g ~}>$.

\footnotetext{
-NOTES

$1<$ http://www.ngapartji.org>.

$2<$ http://www.namatjira.bighart.org>.

3 Yijala Yala has also created content in the following media: films, music, recordings, photographs, books, animation and apps. A major artistic outcome of the project is the beautiful operatic, crosscultural, multi-media performance work Hipbone Sticking Out, which has played in the Centenary of Canberra Festival and the Melbourne Festival, as well as in Roebourne and Perth.

$4<$ https://itunes.apple.com/au/app/neomad-interactive-comic-for/id549058981?mt=8>.

5 <https://itunes.apple.com/au/app/warlu-song-australian-aboriginal/id660554154?mt=8>.

6 <https://itunes.apple.com/au/app/ngurrara-australian-aboriginal/id660560818?mt=8>.

7 <https://itunes.apple.com/au/app/echidna-dress-interactive/id852947501?mt=8>.
} 